\title{
Estudios
}

\section{Gonzalo Higuera* al año de la reforma tributaria}

La Ley de Reforma Tributaria, que supone un sincero, profundo y realista intento por sistematizar y actualizar nuestra Hacienda Pública, necesita, incluso desde los primeros tiempos de su vigencia, una atención grande al logro de una mayor progresividad impositiva y de una más justa redistribución de las rentas; debe apuntar a un equilibrio más real entre impuestos directos e indirectos. La atención en este año se debe centrar de manera especial en la aprobación ponderada y socialmente justa de la tarifa del Impuesto General sobre la Renta de las Personas Fisicas.

\section{ENTORNO DE LA LEY}

I NDISCUTIBLEMENTE que, al lado del nuevo caminar económico español iniciado en el mes de julio de 1959, con la brusca, pero necesaria arrancada del plan de estabilización y subsiguientes etapas que vierten en el actual plan de desarrollo, se ha venido teniendo fija la mirada en otros aspectos de íntima conexión con la política económico-social que necesitaban de igual urgente renovación y puesta al día.

Así, por ejemplo, la Ley de Bases de la Seguridad Social, tan necesaria, estuvo sobre el tapete de la actualidad durante el último trimestre de 1963; a partir del 13 de diciembre se discutió en la Comisión Especial de las Cortes Españolas encargada de estudiar y dictaminar el proyecto, y terminó siendo aprobado por el Pleno correspondiente del mismo mes, todo con una rapidez de vértigo que interpretábamos los españoles como la mejor garantía de una nueva y penetrante cuña en el avance social ineludible. Posteriormente poco se ha edificado so-

* Profesor de Teología Moral de la Universidad Pontificia de Comillas. 
bre aquellos fundamentos, y muchas esperanzas se están desvaneciendo con el pasar inactivo de los meses ${ }^{1}$.

Casi al mismo tiempo se discutía y promulgaba la llamada Ley General Tributaria ${ }^{2}$, con la pretensión, creemos que conseguida casi totalmente, de formular los principos básicos y las reglas jurídicas comunes de la tributación española. Se notan en su contextura las líneas maestras de un atrevido y peligroso intento de codificación, por otra parte necesario. Atrevido, porque la ley así concebida tiene escasos precedentes en la legislación financiera comparada y su redacción implicaba el lanzarse a andar por caminos inexperimentados. Peligroso, porque en el terreno jurídico, la posesión de un código en cualquier materia legal-aparte de las inegables ventajas-muchas veces es el mejor aliado del inmovilismo del derecho con la secuela del desfasamiento entre las verdaderas exigencias reales y la norma estatuida; y en España las actuales necesidades evolutivas no consienten ninguna detención, ni aún mínima. Y también necesario, con solo contemplar la maraña de la legislación fiscal, incluso de principios; los anacronismos, la diferente edad de las disposiciones vigentes al promulgarse la ley, cuyas fechas abarcan desde el post-romanticicismo hasta la era atómica y los años austronaúticos; lagunas o interferencias..., que pedían una serena refundición bien sopesada y simplificadora.

En este esbozo de encuadramiento económico, social y financiero se discute, nace y comienza a aplicarse la Ley de Reforma del Sistema Tributario ${ }^{3}$. Por lo tanto, condicionada más o menos, pero siempre algo, por circunstancias bien concretas y determinadas.

Además, por exigencias prácticas de fácil comprensión, la entrada en vigor de la Ley se previó en forma escalonada, de modo que la mayoría de sus disposiciones comenzaron a regir el $10^{\circ}$ de julio de 1964 , bastantes a principio de este año, algunos aspectos entrarán en vigor a comienzos de 1966, y, en fin, otros cuando se determine por el Ministerio ${ }^{4}$. Corta experiencia, y no total, de vigencia; pero que ya ha provocado los primeros comentarios, roces y reclamaciones en el rodaje inicial de su articulado.

Sin aquel encuadramiento referido y sin esta experiencia práctica, aunque pequeña, las afirmaciones que se quisieran hacer sobre la Ley

1 Escritas estas lineas, la Prensa diaria española de fecha 25-5-65 recoge unas declaraciones del Ministro de Trabajo, señor Rornero Gorría, en Barcelona, en las que, entre otros puntos, se esfuerza por explicar la estática situación de la legislación social española durante los últimos meses.

2 Ley $230 / 63$, de $28-12$, publicada en el $B . O$. E. del 31-12-63.

3 Ley $41 / 64$, de $11-6$, en el $B . O . E$. del 13.

4 Las principales vigencias específicas de la Ley las encontramos en los artícu$\operatorname{los} 5-2,5-3), 6-1), 6-4), 7-1), 24,25-2), 26,28-1), 28-3), 36,38-2), 38-3), 40,46$, $62,63,67,68,95,110,115,156-2)$, en las disposiciones transitorias y en la espera de las Leyes para la aplicación de los distintos tributos, que han de darse antes del 31-12-1965, así como las normas reglamentarias precisas, según los artículos 241-1 y $241-2)$, , respectivamente. 
tendrian menos valor y perspectiva. Por eso hemos aludido a ellos y los tendremos presentes en las siguientes consideraciones, que, naturalmente, se orientarán con una preferencia casi exclusiva hacia los aspectos sociales y morales de la Ley y de sus primeras consecuencias prácticas, marginando más las consideraciones jurídico-fiscales técnicas.

Como es lógico, por no movernos en un campo metafísico o matemático, sino en el terreno de las realidades morales, prácticas y concretas, las afirmaciones que puedan hacerse tampoco podrán tener una exactitud de aquel género, sino sólo la de la apreciación moral que les es propia y les pertenece.

\section{IMPERFECCIÓN RELATIVA DE TODO DERECHO}

De antemano se podía asegurar que el legislador encontraría frente a sí la compleja realidad interrelacionada cada vez en mayores magnitudes y con su fluidez inaprehensible. Necesariamente hubiera podido escribirse a priori que algo se escaparía y que el horizonte de lo perfecto quedaría sin pisar. El hallazgo de lunares no debe sorprendernos y el detenerse morbosamente en ellos sería desleal. Juan XXII en la Pacem in Terris escribía: "Sin embargo, en nuestros tiempos la vida social es tan variada, compleja y dinámica que cualquier ordenación juridica, aun la elaborada con suma prudencia y previsora intención, resulta muchas veces inadecuada frente a las necesidadesn. Incluso contando con la mejor buena voluntad, nunca se podrá poner el signo igual entre los deseos y la realidad. La equivalencia perfecta queda flotando en lo utópico.

El criterio de juicio moral deberá, pues, formularse apoyándose en preguntas semejantes a éstas: a) Negativamente, ise han suprimido todos los aspectos que podrian implicar alguna grave injusticia objetiva?, y b) Positivamente, ¿se da un sensible avance hacia la más completa perfección técnica, por una parte, $y$, por otra, hacia una ética fiscal más limpia? Si las respuestas objetivamente sinceras a las anteriores preguntas resultan ser dos francas afirmaciones in reticencias, a un año escaso de aplicación integral de la Ley, creemos que bastarían por el momento para un juicio crítico sociomoral positivo. Insistamos en la puntualización de por el momento, por la rápica dínámica económica que estamos atravesando, que cambia tan velozmente las situaciones concretas y la consiguiente variabilidad de los datos técnicos sobre los que el moralista ha de construir su dictamen. Las revistas especializadas de economía, comercio, etc., están muy al tanto de esa dinámica variación y estiman suficiente la perspectiva de un semes-

5 PT n. 71. Cfr. Comentarios a la Pacem in Terris, BAC, 230, Madrid (1963), p. 31 . 
tre para poder someter a nuevo análisis la coyuntura con la casi seguridad de encontrar resultados nuevos Seis meses también, en consecuencia, podrian bastar para que unas exigencias fiscales moralmente justas, pasen a ser, en virtud de la dinámica de circunstancias aludida, injustas 0 al menos dudosamente justas por el rodar marginal de una política de salarios y precios, de un desequilibrio entre la oferta y la demanda, de un consumo agigantado 0 sólo especializado en una línea, de la realidad de una inflación más o menos encubierta, o por tantos otros ponderables previsibles o imprevisibles ${ }^{6}$.

\section{RENOVACION $Y$ SIMPLIFICACIÓN NECESARIAS}

Uno de $10 \mathrm{~s}$ primeros principlos de la moral fiscal, aunque no de los más importantes, porque no se entrelaza del todo íntimamente con la justicia o injusticia del impuesto exigido, pide a la legislación financiera sencillez y actualización. En realidad ambas características son reclamadas por cualquier clase de ley a todo legislador. Pero en las fiscales la exigencia se agudiza porque el deber tributario no es en si psicológicamente grato y hay que facilitar su cumplimiento con más extremoso cuidado y delicadeza.

No es ningun secreto que el anterior sistema fiscal español se hallaba anticuado $y$ deformado. $X$ publicamente se reconoce en las exposiciones de motivos de las dos Leyes Tributarias fundamentales, así como en declaraciones autorizadas y en los mismos debates tenidos en las comisiones de las Cortes. Durante muchos años de historia no hubo más remedio que recurrir para las inaplazables actualizaciones iscales a disposiciones de emergencia, porque la inestabilidad política no permitio en el ultimo siglo y medio un hueco a la tranquilidad necesaria para una renovación más a fondo. Retazos y adherencias legislativas, que, unidas a los inevitables defectos de origen, hacían per. der por dias flexibilidad a todo el conjunto, y creaba una especie de reumatismo en la legislación tributaria con movimientos contrahechos y crujientes en el momento de la aplicación práctica. La multiplicidad de tantas disposiciones accesorias al sistema sustraía también luz y sencillez a todo el conjunto en un buen grado, molestaba al contribuyente, daba facil pie a distintas interpretaciones, incluso entre el mis-

- De todas formas habria que distinguir claramente un juicio de carácter moral o técnico de la mistria ley en abstracto o de los meses transcurridos ya vigiendo, may incompleto pero posible, de un primer juicio más exhaustivo de todos los efectos prácticos que puede provocar la Ley, imposible por ahora, mientras no transcuran dos o tres años. $\mathrm{A}$ este último se refieren las afirmaciones de los in formes económicos o bancarios relativos al ano 1964 , cuando no quieren com" prometerse dando una opinión sobre el nuevo sistema fiscal español y alegan que es muy pronto para apreciar las consecuencias prácticas que puedan derivarse de la nueva ordenación. Así entendida la inhibición crítica, completamente de acuerdo. 
mo Cuerpo de Inspectores de Hacienda y, sobre todo, abría incontables escapes a la injusticia objetiva del mismo impuesto y al fraude de los menos escrupulosos con lo que quedaba construida una ancha plataforma para la justificación moral de la evasión tributaria y la deseducación ciudadana. Las leyes de 1957 y de diciembre de 1963 supusieron avances plausibles, pero el sistema en su conjunto quedaba en pie con los inconvenientes apuntadas y la exigencia de una renovación total, cada vez más viva.

En contraposición, al menos teóricamente, la simplificación y claridad en el nuevo sistema tributario es, sin duda, notable. Podemos probar la afirmación viendo cómo el articulado de la ley se reduce pronto a un sencillo esquema sistemático de diafanidad cenital, como sigue:

Los IMPUESTOS DIRECTOS han quedado, pues, esquemáticamente reducidos a dos, o, si se quiere, a tres gruesas ramas bien escogidas y estudiadas: Impuesto sobre la Renta: a) De personas físicas, y b) De las sociedades $y$ entidades juridicas e Impuesto sobre las Sucesiones. $\mathrm{Y}$ los habitualmente complicados IMPUESTOS INDIRECTOS se agrupan también en dos brazos exclusivos de nueva creación: Los impuestos indirectos sobre transmisiones patrimoniales $y$ actos juridicos documentados y sobre el tráfico de empresas.

Si a ello añadimos el contenido de la disposición final de la ley, cumplimentada en el decreto $4132 / 64$, de 23 de diciembre de 1964, promulgando la tabla de vigencias y derogaciones de disposiciones legales anteriores, la sensación de simplificación y poda legal aumenta considerablemente: 303 epigrafes entre las derogaciones y 192 entre las modificaciones, significan un aligeramiento notable.

$$
* * *
$$

Sin embargo, la sencilla esquematización legal que hemos expuesto se implicará notablemente en la práctica. En sí misma la ley lleva dentro gérmenes que han de proliferar de forma necesaria. Cada tributo singular está esperando la oportuna ley a la que ha de seguir el correspondiente reglamento; después no faltarán las órdenes ministeriales, resoluciones, aclaraciones, etc. ${ }^{7}$. Sabemos que técnicamente esta escala descendente de normas legales y administrativas se hace precisa, pero en lo que se quiere fijar ahora la atención es en que no se haga inconsideramente, de forma inorgánica e incoherente, sino que en el futuro haya periódicas simplificaciones y refundiciones materiales de las normas en vigor, no dejando atrás disposiciones vigentes con fecha

7 Cfr. art 9 de la Ley General Tributaria como norma general, y, p. ej., los arts. $28,40,48,64,68,110,120,185 \ldots$, de la Ley de Reforma del Sistema Tributario. 


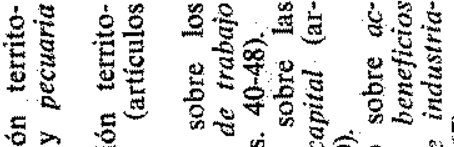

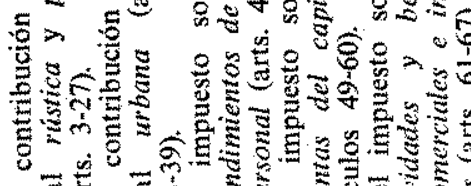

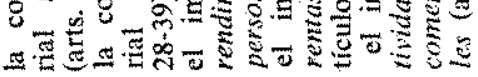
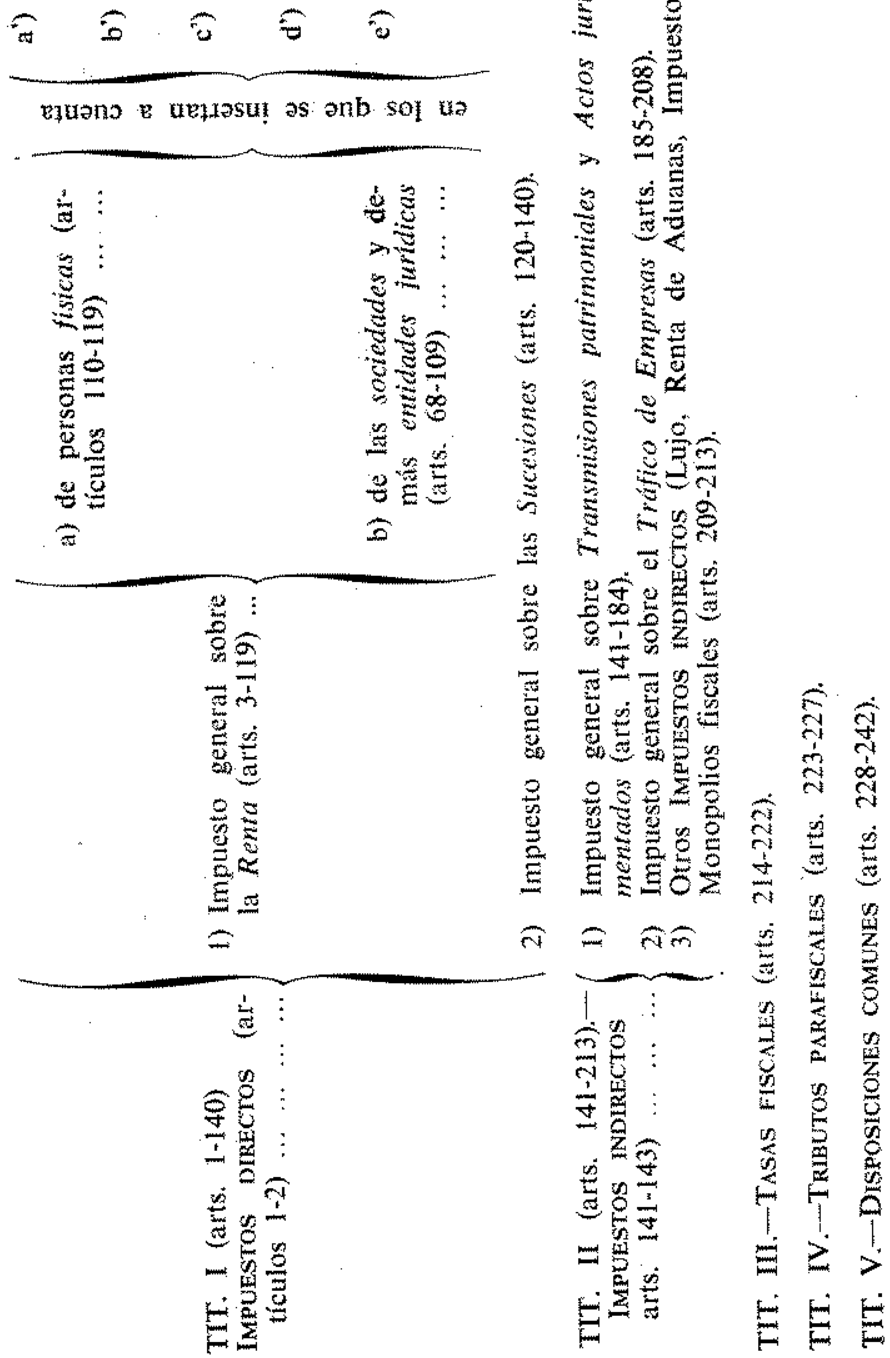
excesivamente pretérita, quizá sólo en unos cuantos artículos, mientras la mayoria o una parte considerable son derogados ${ }^{8}$. Estamos en vísperas del despliegue de disposiciones administrativas necesarias para las dos leyes fiscales básicas españolas promulgadas en los últimos años. Y, por lo tanto, se está a tiempo de evitar la caída en esa posible y probable fronda legal financiera futura. El camino iniciado de simplificación, no ha concluído, sino que sólo ha dado los primeros vacilantes, aunque valerosos pasos, que hay que robustecer y dirigir por la trayectoria iniciada ${ }^{9}$.

8 No es ninguna novedad en la legislación española, y preferible por las muchas ventajas que encierra, el sistema que normalmente se viene empleando para renovar los artículos del Código Civil que exigen ser cambiados: una ley desmonta el texto del artículo o artículos ya improcedentes, sustituyéndolo por la nueva redacción que queda insertada en el espacio que ha dejado libre el derogado. Con ello el Código Civil mantiene el orden de su articulado, sigue siendo sustancialmente el mismo y al mismo tiempo puede estat en continua evolución según lo exijan las circunstancias. Fuera de la legislación codificada, más apta para este sis tema, encontramos también un ejemplo elocuente de la última Ley de Arrendamientos Urbanos, 40/64, del 11-6-64 (B. O. 12-6), que sólo promulga los artículos modificados por las exigencias del actual reajuste de rentas, etc. Más tarde, el Decreto 4104/64, del 24-12-64, del Ministerio de Justicia (B. O. 24-12-64), publica ya el texto refundido de la Ley de arrendamientos urbanos por una parte plenamente actualizada con la última reforma, y, por otra, desistiéndose «de dar una nueva estructura al cuerpo legal..., porque bien meditadas las cosas, tal cambio radical en la sistemática de la Ley podría contribuir más a entorpecer y dificultar la misión del intérprete, habituado a encontrar la norma en el lugar en que durante tantos años la hallaba, que a simplificar el manejo de sus disposicionesm. Este estilo de actualización legal manteniendo al mismo tiempo la estructura de la disposición por los motivos que nos acaba de indicar el Ministerio de Justicia, no es desconocido por el Departamento de Comercio, sino utilizado frecuentísimamente en materia de íntima relación con el Ministerio de Hacienda, como es la Renta de Aduanas y las modificaciones de partidas y subpartidas del Arancel.

El camino está abierto y experimentado en otros campos legales. Comprenderemos que las dos leyes fundamentales de la Hacienda española adquiririan así un buen volumen ( 6 excesivo?). Supuesta la Ley General Tributaria, subseguiria otra Ley del Sistema Tributario, única, que en su articulado debería abarcar necesariamente la estructuración de cada tributo de manera completa en cuanto a lo preciso en rango de ley. La esclerotización o inactualidad se evitaría con el desmontaje de artículos en la forma indicada. Y no se daría una redacción como la actual del art. 28 de la Ley de Reforma: "...la Contribución territorial urbana se exigirá con las normas por las que actualmente se rige, con las modificaciones que resulten de la presente Leyn, redacción repetida de manera unifomre en los artículos de la nota anterior y en algunos otros de la Ley.

Véase detenidamente la tabla de vigencias del Decreto 4132/64, ya citado, en el que encontramos líneas como éstas: Derogado el art. $10^{\circ}$ de la Ley de 23 de mayo de 1845; modificado el art. $50^{0.5}$ de la Ley de 18-6-1885; derogado el Real Decreto-Ley de 15 de diciembre de 1927 en sus arts. $30^{\circ}, 40^{\circ}, 60^{\circ}, 7 .^{\circ} 8.0,10$, $12,13,17$ y 18. $\mathrm{Y}$ así, líneas semejantes por decenas. La misma Ley tiene cláusulas derogatorias del mismo estilo, como, p. ej., el art. 109, que deja sin vigor el art. $20^{\circ}$ de la Ley de $18-12-46$, el art. $20^{\circ}$ de la Ley de $31-12-41 ;$ los arts. $10^{\circ}$ y $30^{\circ}$ de la Ley da 4-5-48, etc., etc.

9 La labor simplificadora no es exclusiva de la legislación financiera. La necesidad se ha sentido en otros campos preceptivos españoles que también recono- 
Consideraciones paralelas podiamos seguir haciendo a propósito de la unificación de tipos, bases imponible y liquidable, etc, dentro de las posibilidades prácticas que se ofrezcan para ello.

Pero en cualquier forma la exigencia es insoslayable, y la tendencia debe verse hecha realidad poco a poco. Ese es, en primer lugar, uno de los datos con los que debe contar necesariamente el moralista para poder juzgar, desde su campo, si la obligatoriedad teórica en conciencia de satisfacer los tributos ha descendido a la práctica por este capítulo de la claridad y de la simplificación de la legislación fiscal, no sólo en las leyes básicas y fundamentales, sino también en todas las determinaciones posteriores, aun de rango infimo. Efectivamente, la obligación en conciencia exige la justicia del tributo exigido, y que además aparezca al contribuyente dentro de 10 posible. $Y$ difícilmente se verá en medio de una legislación enmarañada.

Además, se relaciona fntimamente el derecho del ciudadano a estar informado de 10 que se 1 exige, cómo y para qué se le exige, a un nivel medio que difícilmente se lograra en una complicada trama de disposiciones. Hay que quitar el pretexto para que en las consultas concretas de conciencia sobre aspectos fiscales se incluyan con razón trases como. (No nos entendemos entre tantas normas", Imposible conocer 10 que se legislan, \& veces se dan contradicciones y no se sabe qué hacer, aNi los mismos organismos oficiales o sus funcionarios dominan 10 preceptuado y se llegan a contradecirn, etc. No es necesario para ello contar con el alarde de ingenio del economista y financiero Jacques Rueff en el discurso de ingreso en la Academia francesa queriendo demostrar el parentesco cada dia más intimo entre la economía y la poesía. Nos bastará con que el pensamiento y las disposiciones financieras, además de la sencillez, eviten en lo posible mostrar una excesiva especializacion del lenguaje y de aspectos técnicos al alcance de los entendidos, pero no de la mayoria y de la gran masa de ciudadanos para quienes se legisla puesto que a todos ellos se va a reclamar parte de su dinero para el bien común y todos ellos están obligados al cumplimiento de la ley, que, en consecuencia, debe bajarse, incluso en su expresión y estructura, hasta esa mayoría que tiene un derecho cierto a ello para no pagar a ciegas, sin comprender, sin poder calcular, más cuesta arriba. La ciencia financiera, lo mismo que la ciencia económica, en palabras escritas hace poco, "para servir y ayudar de verdad a los hombres ha de pasar cada vez más del ámbito limitado de los técnicos y especialistas al amplio y profundo del intelectual y humanistas

cen, al dar sinceramente los primeros pasos, que hay mucho camino que recorrer. Invitamos a leer la magnifica exposición de motivos sobre estos aspectos de la Ley $31 / 65$ del $4-5-65(B, 0$ del $5-5-65)$ relativa a las retribuciones de los funcionarios públicos.

10 Funes Robert, M, Un programa para la economía española, Madrid, 1965. 


\section{PROGRESIVIDAD Y ASPECTO SOCIAL DE LA LEY}

No hace aún muchos años se sostenía como fin único de la recaudación fiscal el obtener los fondos necesarios para los gastos públicos, que ciertamente habian de atemperarse a las necesidades exigidas por el bien común.

Esta visión finalista de la Hacienda pública ha ensanchado poderosamente: sus perspectivas en época bien reciente. En concreto, para España encontramos de una manera explícita la formulación de funciones instrumentales reconocidas al impuesto, además de las recaudatorias, en la misma Ley General Tributaria ". No se discute, ya que la Hacienda Pública pueda y deba ser también un instrumento de política económica y social y de equilibrio y progreso nacional. Antes, preferentemente, en cuanto a la justicia distributiva, la legislación financiera cumplía con atender a la distribución equitativamente proporcionada de las cargas necesarias que imponía a los ciudadanos; ahora las exigencias de la justicia distributiva añaden a aquella distribución proporcionada de cargas una atención ineludible a la distribución más justa de la misma riqueza nacional ${ }^{12}$. Nuestra época es consciente que la recaudación tributaria puede interferir poderosamente la marcha y planes económicos y que debe ajustarse de forma más ceñida a la idea social ${ }^{13}$.

Por eso ya no se podrá juzgar en adelante ningún sistema o ley tributaria sin considerar en su justa valoración las repercusiones y finalidades sociales de lo que exigen.

Más aún, los fines y repercusiones marginales de la tributación, sobre todo en el aspecto redistributivo, en fuerza de las circunstancias

11 Exposición de motivos, n. 2, pár. 3: «...al mismo tiempo que se reconoce la función instrumental, que, sin preterir los dictados de equidad y generalidad, puede cumplir el tributo al servicio de la política económica y social del país.) Cfr. también el art. $3^{\circ}$ \&a ordenación de los tributos ha de basarse en la capacidad económica de las personas llamadas a satisfacerlos y en los principios de generalidad y equitativa distribución de la carga tributaria", y el art. 4.* "Los tributos, además de ser medios para recaudar ingresos públicos, han de servir como instrumentos de la política económica general, atender a las exigencias de estabilidad y progresos sociales y procurar una mejor distribución de la renta nacional.

12. Sobre el papel finalístico del impuesto como redistribuidor de la renta nacional, cfr. el número monográfico de la revista Información Comercial Española, núm. 532, de diciembre de 1962. Más recientemente se ha tocado el tema en la XIII Semana de Estudio de Derecho Financiero celebrada en Madrid, marzoabril 1965. Las implicaciones morales de este aspecto redistributivo del tributo se encientran aún, a nuestro modo de ver, sín posición definitivamente para las circunstancias de nuestro tiempo. Algo se ha intentado hacer en la Semana de Derecho Financiero aludida, pero merecería la pena que dedicáramos más adelante, con tiempo suficiente y sustantividad propia, un artículo exclusivo.

13. Cfr. Barrera de Irimo, A., en Introducción General a la obra Comentarios a la Ley de Reforma del Sistema Tributario, Madrid, 1964, pp. 1-6. 
económicas actuales, se entremezclan con los círculos morales y éticos, perdiendo así una posible indiferencia ante las conciencias. En virtud de ello podemos encontrar alusiones especiales en la doctrina pontificia y en la jerarquía española ${ }^{14}$.

\section{LA JUSTICIA SOCIAL COMO OBJETIVO}

La nueva andadura de la legislación española de la Hacienda pública, teóricamente, como acabamos de insinuar, empieza a desperezarse por tales derroteros. De otra forma, sería inadmisible. Antes que nada se nos ha repetido oficialmente a los españoles en distintas ocasiones, y siempre por personas autorizadas, que la última reforma tributaria no iba dirigida a obtener mayor recaudación ${ }^{15}$, lograda en 1957 , con la reordenación fiscal que para este fin se redactó en aquella fecha. Naturalmente que, siendo esto así, saltan a primer plano, aparte de un aspecto técnico, los fines subsidiarios modernamente atribuidos y relacionados con la imposición: "La ley pretende acomodarse a unos principios racionales de técnica tributaria, pero también que las motivaciones económicas y sociales participen igualmente en dicha ordenación, de manera que las directrices politicas no tengan un reflejo esporádico en el sistema fiscal, sino que de modo permanente el mecanismo de los ingresos públicos se ponga al servicio de los objetivos del crecimiento económico y de la justicia social ${ }^{16}$,

Sin embargo, las manifestaciones positivas hasta ahora, sin querer recortar en nada su verdadera significación dentro de las posibilidades actuales, hay que reconocer que son muy rudimentarias, aun comparándolas tan sólo con el ideal realista de una meta de mediana perfección concorde estrictamente con nuestro verdadero rango nacional. Prueba de ello es la misma relación que oficialmente se nos hace de las conquistas realizadas o que se pretenden: inversión de los llamados Fondos Nacionales, con los gastos del Patronato de Igualdad de Opor-

14 Entre otros documentos pontificios, efr. Mater et Magistra, núms. 132-33, 2.a ed, BAC, Madrid, 1963. Pero especialmente para España la Declaración de los Metropolitanos Españoles, en Ecclesia, II, (1956), 317-320, con los editoriales de la misma Revista en II (1956), 311, y II (1956), 60, y Discurso de Clausura de Monseñor Casimiro Morcillo en la XIII Semana de Estudios de Derecho Financiero ya citada.

15 Esta afirmación se ha hecho repetidas veces por el Ministro de Hacienda, senor Navarro Rubio, en discursos transcendentales y en entrevistas de prensa, tenidos durante el tiempo de preparación y discusión de la Ley de Reforma del Sistema Tributario. Cfr., p, ej., la rueda de Prensa del 13-11 63, etc. También en la defensa de la Ley ante el Pleno de las Cortes por el señor Sánchez Cortés el 6-6-64 y el subsigutiente discurso del Ministro de Hacienda en la misma sesión plenaria.

16 Cfr. exposición de motivos de la Ley de Reforma del Sistema Tributario, en el epigrafe Sentido social de los impuestos. 
tunidades; la elevación general de los mínimos exentos; intensificación de los medios para la protección a las familias; estímulos a la formación del ahorro, a la mejora de las inversiones productoras; a la exportación, etc. Todas ellas apenas han comenzado a iniciar la marcha, que debe seguir marcando un paso firme y decidido en todos los frentes. Porque prácticamente nadie se sentirá satisfecho con lo conseguido, y si los cauces abiertos por la Ley en estas líneas no se recorrieran, la desilusión sería grande y mayor aún la responsabilidad. En todos ellos la corta vigencia de la Reforma no da plataforma más amplia para contabilizar lo hecho, sino apoyo firme para exigir que se cumpla con energía lo que jurídicamente se ha promulgado. Es obligación, y obligación que el poder legislativo ha reconocido, por lo que la culpa posible de omisión no podría alegar ninguna atenuante de ignorancia o imposibilidad legal en los próximos doce meses y años sucesivos.

\section{UNA EXIGENCIA MORAL: LA PROGRESIVIDAD DEL IMPUESTO}

De todas formas es muy posible que donde mejor se pueda valorar y tomar el pulso a los aspectos económico-sociales de un sistema tributario sea en su progresividad. Por su específica importancia e interés hemos querido separarle de las demás facetas socio-económico-fiscales que acabamos de sopesar. $Y$ por su importancia también ha tenido que ser considerado de manera destacada en las normas positivas de la Reforma.

La progresividad es una exigencia ineludible moralmente, que entra de lleno en la justicia distributiva al menos, porque también está muy relacionada con la legal $y$, por supuesto, con la justicia social. Tiene, por lo tanto, complejas implicaciones morales que se potencian en dificultad al sobreponerse en el análisis, las consecuencias económicas y sociales que se prevén como posibles al practicarla de una forma u otra, o sencillamente al prescindir de sus postulados.

El principio moral de justicia en que de manera más clara se apoya la progresividad es el enunciado "a cada uno según sus posibilidadesn. $\mathrm{Y}$ no tiene más limitaciones extrínsecas socio-económicas dignamente aceptables en moral para no ponerlo en práctica o ponerlo sólo parcialmente, que evitar un mayor mal al bien común en la coyuntura económico-social concreta de que se trate.

Pues bien, en este punto de la progresividad tan trascendental para dictaminar sobre la justicia de cualquier sistema tributario queda mucho que hacer en la práctica, al igual que en los puntos anteriores a los que nos hemos venido refiriendo. Pero además aquí parece que tampoco teóricamente se puede aceptar la perfección inicial de otros 
aspectos con tanta faclidad Sencillamente, se afirma que el sistema tributario español no es progresivo, ni siquiera proporcional, sino regresivo, incluso en los mismos principios y normas legales.

De hecho el legislador al tocar este punto en la exposición de motivos de la Ley nos dice:

Entre los principios inspiradores de esta nueva ordenación del sistema tributario español, el Proyecto de Ley trata de establecer las bases para una distribución más progresiva de la carga tributaria. Es esta cuestión que ha de juzgarse, no en función del mayor o menor grado de progresividad de diversos tributos, sino del que resulte del conjunto del sistema fiscal. Y no sólo por razón de la estructura de las tarifas, sino por la generalidad en los criterios de su aplicación, tanto respecto al gravamen de las rentas y gastos de toda naturaleza como por la eficacia administrativa con que todos ellos sean llamados a tributar. Este perfeccionamiento de nuestro sistema tributario, fundado no sólo en principios de técnica físcal, sino en conveniencias de política económica y social, ha de ser paulatinamente conseguido a través de una aplicación más eficaz de los impuestos más distributivos y de una estructuración más justa de su propio contenido, lo que implica también una profunda y paulatina revisión de los mírimos exentos de tributación que en la Ley se inicia o prevé decididamenten ${ }^{17}$.

\section{¿ES PROGRESIVA LA NUEVA LEY?}

El articulado legal está en perfecto acuerdo con el plan que se nos traza en el parrafo transcrito. No añade ningứn dato nuevo que pudiera dar más luz a un modesto comentario.

Ahora bien, las palabras repetidas obnubilan bastante la primera afirmación acerca de la trascendencia que se quiere dar al principio de progresividad en todo el sistema. En efecto, se dice a renglón seguido que hemos de juzgar la progresividad no por el grado mayor o menor que apreciemos en un tributo aislado, sino: a) En todo el conjunto, y b) Por el criterio de aplicación y eficacia administrativa más que por la estructura de las tarifas.

Nos tememos que estos criterios sean bastante oscuros para la generalidad de los contribuyentes e incluso de especialistas, $y$ que infundan sospechas de difícil disipación. .Cómo va a ser progresivo el conjunto en su suma si no son progresivos los sumandos? Por otra

17 Exposicion de motivos citada, en el título Progresividad. 
parte después de la simplificación, ¿no quedamos en que sólo permanecen realmente dos o tres impuestos directos y otros dos indirectos? ¿Tan difícil va a resultar el apreciar la progresividad en ellos? Además la mayoría de los españoles vive y deberá vivir cada vez más con el fruto de su trabajo, y se pregunta: ¿Para esa mayoría de españoles no va a resultar en la práctica progresivo el sistema porque su única manera de tributar a través del impuesto sobre el rendimiento del trabajo personal pueda no ser progresivo?

Acerca de la progresividad en el impuesto de sucesiones se dijo que el acento se pondria más que en una nueva vuelta al torniquete de los tipos en la exigencia más rotunda y fiel de la exacción, con el combate a fondo de las ocultaciones y fraudes o subterfugios que se vienen practicando; es decir que nos encontrariamos ante un caso típico de aplicación de lo que acabamos de ver se ha llamado ueficacia administrativan. ¿Es bastante esto para la debida progresividad en este tributo? ¿La pretensión es lo suficiente clara y convincente para el contribuyente? Ciertamente, nos tememos que no, sin meternos en más profundidades y sin queder tampoco asegurar, en el plano teórico en que nos encontramos de este punto, que se pueda dar moralmente un sí o un no caegórico. Se reciben dictámenes técnicos encontrados sobre si realmente en teoría el sistema tributario español es progresivo en su conjunto al menos con el minimo requisito, pero indispensable para salvar su justicia. No debe extrañarnos la disparidad de dictámenes técnicos ${ }^{18}$. Pero sí hay que anotar que esa bifurcación de pareceres engendra una difícil posición a la solución moral clara y única. Porque el principio ético inmutable adquirirá tonalidad diferente, según se aplique a uno o a otro de los dos pareceres opuestos : es justo, $y$, por lo tanto, obligatorio en conciencia o no es justo totalmente $y$, por lo tanto, tampoco totalmente obligatorio en el fuero interno.

En medio de esta posible duda teórica sobre la existencia de la suficiente progresividad, al menos en grado mínimo, requerida por la justicia distributiva, hay algunos otros factores laterales que pueden iluminar algo la neblina. Primero: la presunción a favor de la ley. Si el dictamen técnico-teórico se bifurca, parece que prácticamente en medio de la duda nos podriamos inclinar a favor de la justicia de la ley presumiendo la suficiente progresividad (al menos en grado minim mo) y aplicar a esa presunción el criterio moral. Segundo: la necesaria imperfección de todo sistema legal en nuestros tiempos, como

: 18 En realidad se pueden dar y se dan en cualquier aspecto económico. Precisamente en estos últimos tiempos podemos recordar las distintas opiniones que han aflorado en el campo nacional sobre el empleo de las divisas españolas, la devaluación de la peseta en 1959 , la interpretación del adéficito crónico de los presupuestos españoles, etc., que han saltado incluso hasta la prensa diaria y at hombre de la calle; $y$ en el campo internacional, la disputa sobre las funciones monetarias del oro, sa exclusividad como único patrón monetario compartido, etc. 
hemos dicho en el subtítulo primero de este mismo trabajo. $Y$ que aqui está reconocida explícitamente por la Ley, que sabe ha de evolucionar en mejor paulatinamente de una manera decidida ${ }^{19}$. Y tercero: que el legislador tiene aún la última carta en su mano, que, de jugarse bien, inclinaría de una manera decidida, teóricamente, la balanza del lado de la progresividad, al menos para poderse afirmar que se da en el sistema español, aunque sea de forma imperfecta, pero clara. Nos referimos al artículo 114 de la Ley ${ }^{20}$. A partir de 1 de enero de 1966 el Impuesto General sobre la Renta de Personas Físicas entrará plenamente en vigor y se exigirá mediante los impuestos a cuenta enunciados en el artículo $2:^{\circ}$ (contribución territorial sobre la riqueza rústica y pecuaria, sobre la riqueza urbana, sobre rendimientos de trabajo personal, sobre rentas de capital y sobre actividades y beneficios comerciales e industriales) que poco importarán sean progresivos o no en sí mismos considerados, si realmente después la aplicación de la escala a la que hace referencia el artículo 114, que está en espera de ser aprobada, previa presentación a las Cortes, va a ser realmente progresiva. Atención a este punto tan interesante que debe resolverse en el presente año. Es crucial para que, en relación con los impuestos directos, podamos decir que el sistema tributario español es justo o injusto en cuanto a la progresividad.

\section{Progresividad y FoRMación DE CAPTTAL}

Además de la proporción recaudatoria que se dé en España entre los impuestos directos e indirectos, que nos podría indicar algo sobre el aspecto social de la tributación nacional, pero que dejamos para el párrafo siguiente, nos queda aún por indicar con breves palabras si actualmente una falta de progresividad o una progresividad deficiente queda justificada como mal menor necesario por alguna razón extrínseca e independiente a la misma tributación. Desde luego que tal razón, de existir, no sería directamente social, pero sí podría darse alguna económica. En concreto, la pérdida de estímulo personal o, sobre todo, la necesidad de capitales, cuya formación o atracción se vería duramente afectada.

También aquí divergen las opiniones. En general, el elemento más capitalista y económico tiene a la progresividad como causante de un

19 Cfr. el subtítulo de la exposición de motivos de la Ley correspondiente a la Progresividad.

20 "La tarifa del Impuesto general sobre la Renta de las Personas Físicas será aprobada mediante Ley votada en Cortes, para lo cual el Gobieno presentará el oprtuno proyecto...n 
daño considerable y real, mientras que los que prefieren detenerse más en el aspecto social no ven tanto inconveniente. No nos detenemos más ahora en ponderar las razones en favor o en contra de cada una de las posiciones, en especial porque autorizadamente se ha dado un parecer que zanja la cuestión en una línea determinada para las actuales circunstancias, son unas palabras del Ministro de Hacienda:

"La resistencia de quienes... (presentan) un supuesto dilema entre la distribución de la renta y la formación del ahorro que no se debe ciertamente ignorar, pero tampoco sobrevalorar, porque la experiencia prueba la perfecta compatibilidad entre ambos objetivos. En nuestro caso esta razón no se puede alegar ni siquiera a efectos dialécticos... Pero, anotada esta excepción, no hay razón moral, social, ni económicamente valedera, capaz de enervar el natural desarrollo de una imposición directamente orientada hacia una más justa distribución de la riqueza..., para que nos enfrentemos de una vez ante una responsabilidad moral, económica, social y politica, que no admite dilación, ni se excusa con paliativos... Hoy día el Estado se encuentra con que tiene en sus manos la clave del problema de la difusión de la propiedad mobiliaria. Y si el Estado puede, debe hacerlo, porque es técnicamente posible, socialmente deseable $y$ politicamente conveniente... ${ }^{21}$.

Después de estas palabras de una autoridad y de un técnico, se da un apoyo fuerte para el dictamen moral. Hay que ir adelante por el camino de la progresividad en las actuales circunstancias también.

$$
* * *
$$

Hemos hablado del aspecto social y progresivo de la Ley de Reforma del Sistema Tributario desde el punto de vista teórico, en donde muchas apreciaciones no alcanzan la claridad que desearíamos. En consecuencia, más dificultad se hallará prácticamente, aunque las ûltimas autorizadas palabras transcritas sirven de anillo de unión y establecen una pequeña pero sólida base para actuar. En los meses que quedan de año, la ley que necesita el desarrollo del artículo 114 y las restantes disposiciones necesarias por otros capítulos tienen la palabra, y ciertamente de peso, para una futura y más definitiva valoración moral.

21 Palabras del Ministro de Hacienda ante el Pleno de las Cortes el día 22 de diciembre de 1964. El subrayado es nuestro. 


\section{PROPORCIÓN ENTRE IMPUESTOS DIRECTOS E INDIRECTOS}

Verdaderamente llamativa resulta la proporción entre lo recaudado por impuestos directos e indirectos 22 . Precisamente en ese porcentaje encuentran fuerte argumento los sostenedores de la regrsividad del sistema tributario español, argumento para afirmar un fallo en la justicia por ese lado. Como indicio telativo no está mal, porque en absoluto los impuestos indirectos, en si, pueden ser admitidos moralmente si no estan dañados por algunas otras crecunstancias que los hagan injustos.

22 E difill establecer la verdadera proporción entre impuestos directos e indrector en nuestra Hactenda Pública sin una estudiada discriminación de las es tadistreas presupuestarias y sobte todo de la nueva configuración en las partidas del presupuesto de ingresos ya acomodadas a la reciente Ley de Reforma Tributaria y que, en consecuencia, no coinciden exactamente con las antetiores, haciendo por este capitulo mas dificil aún la comparación. Ya en el año 1961 las estadísticas internumpieron la serie de partidas que se venian realizando con otra nueva para presentar las cantidades líquidas ingresadas en los respectivos presupuestos del Estado De todas formas una primera impresión nos pueden dar las cifras que tomamos del Anuaro de 1964 y del I.NE, c. 7, p. 258 . Para 1964 utilizamos cifras provisionales, y para 1965 el avance de ingresos prestiptestados, hecho público a primeros de abri ditmo.

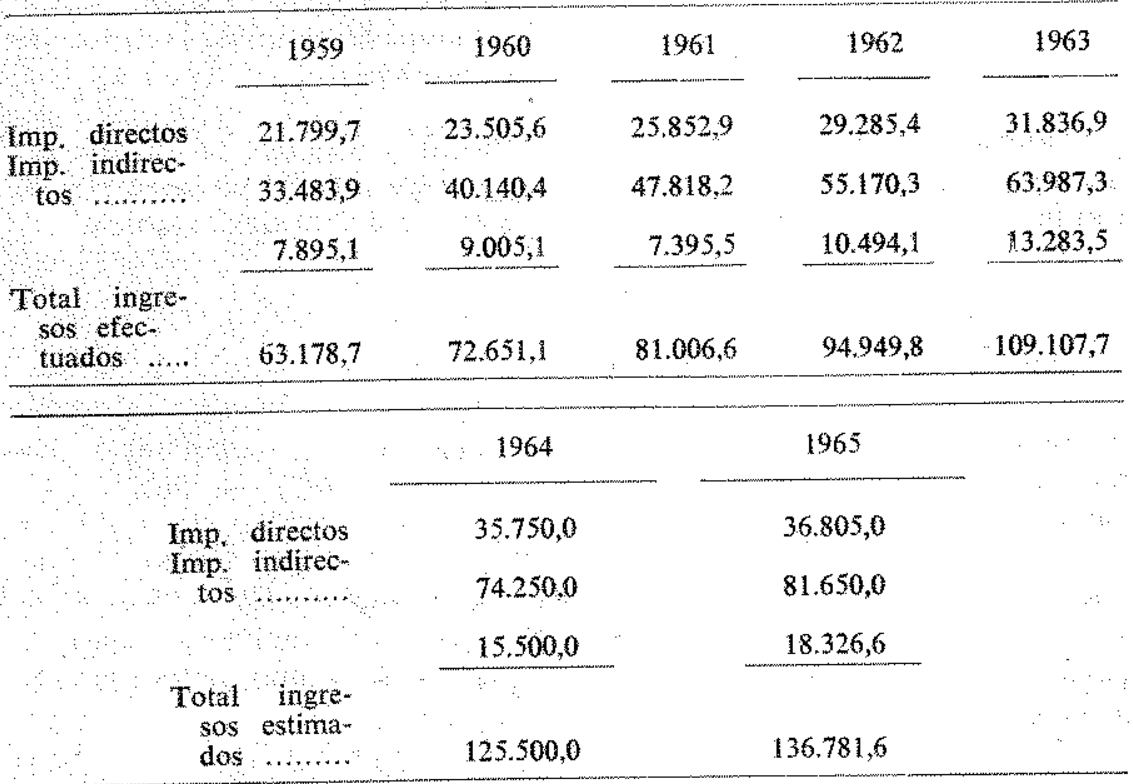

N. B Las cifras están dadas en millones de pesetas.

En totros conceptos están comprendidas las Tasas por servicios prestados, operaciones financieras, enajenaciones; ingresos patrimoniales y otros ingresos: 
El problema no es nuevo, y se viene planteando a lo largo de las distintas epocas históricas. Podemos afirmar, como dato curioso, que los grandes moralistas de los siglos XVI y XVII tuvieron que enfrentarse con él al tratar de la justicia del impuesto. En general, se muestran más dificiles en conceder una justicia a la tributación indirecta, 0 quizá sea mejor decir que son más numerosas las condiciones que se exigen para que la imposición indirecta sea plenamente justa comparada con la directa. Hay que considerar el posible traslado y la incidencia final del impuesto indirecto, distinta a la que el legislador pretendía: que los artículos o actos gravados pueden ser muchas yeces de primera necesidad o también que tales tributos pueden recaer en más ocasiones de las que se piensa en personas de nivel económico por debajo de la línea que fiscalmente debe ser intocable. Sin embargo, se reconoce que la imposición indirecta comporta clertas ventajas, como la facilidad y economía en la recaudación, que la exacción es menos sensible y la presunción de que si los contribuyentes fueran preguntados escogerían muchas veces la tributación indirecta por las razones apuntadas y otras paralelas ${ }^{23}$. Desde luego que no todas estas razones serían válidas para nuestros días, pero sí queda en pie siempre que aunque más peligrosa, la recaudación indirecta puede ser justa, aunque de alguna manera debe suplirse su poca eficiencia para una redistribución más equitativa de la riqueza a nivel nacional en las presentes circunstancias.

\section{AUMENTO DE LA IMPOSICIÓN INDIRECTA}

De todas formas, utilizando las cifras que se transcriben en nota, $y$, por supuesto, teniendo en cuenta las indicaciones que se hacen en la misma, las cifras de los ingresos presupuestados para 1965 dan materia para alguna seria consideración que fundadamente pone en duda el aspecto progresivo de nuestro sistema tributario.

Efectivamente, el total de ingresos calculado para el presente año supone un aumento que mantiene el ritmo sostenido en precedentes ejercicios, aunque un poco frenado. Sin embargo, los impuestos directos se mantienen prácticamente en una cifra equivalente a la del año anterior, lo mismo que la partida "otros conceptosn, con lo que resulta que el aumento ordinario del presupuesto español este año carga de manera casi exclusiva en los impuestos indirectos. Empeora el porcentaje proporcional de ingresos directos e indirectos con relación al total, con lo que se hace más llamativa esta situación española. Es

23. Aunque muy incompletamente, porque el tema sobre la causa material para la justicia objetiva del impuesto es muy amplia en los moralistas clásicos y dificil de abarcarla en su conjunto casuístico, hemos tratado del tema en el artículo $T r i-$ butos y Moral en los siglos XVI y XVII, Miscelánea Comillas 40 (1963), 7-50. 
verdad que se puede puntualizar mucho al contabilizarse las partidas presupuestarias con arreglo a un nuevo sistema. Así, podemos tener en cuenta que, entre los impuestos indirectos, uno 3.400 millones pertenecen al arbitrio provincial que se contabiliza ahora junto con la cantidad obtenida por el impuesto general sobre el tráfico de empresas, y que no figuraba en presupuestos precedentes. De la misma forma habría que rebajar otras cantidades. Aun así, la proporción que se había venido teniendo en años precedentes, en el mejor de los casos, seguiría manteniéndose: es decir, de uno a dos a favor de los impuestos indirectos, que sobrepasan en el doble a los directos. ¿Podemos quedarnos tranquilamente confiados ante este resultado? Sinceramente, no. Hay mucho camino que recorrer, establecer comparaciones con la proporción que se da en otros países y lanzarse a buscar al menos una línea más horizontal de porcentaje, un 50-50, dentro de lo posible y con rapidez para no rozar la moral de manera permanente, con el peligro de que se produzca si no una herida, al menos una escocedura sostenida, que proceda principalmente del campo de la sociología y de la insostenible distribución de rentas actuales. Hay que entender esto con cierta ancha comprensión, porque entendemos fácilmente que la Hacienda Pública se va a encontrar también entre la espada y la pared en el campo de la imposición directa, como enseguida veremos ${ }^{24}$.

Y penetrando más de lleno en algún punto relativo a la imposición directa propiamente dicha, el punto fundamental es aquel en el que tantas veces se ha insistido por técnicos, autoridades e incluso moralistas. Se precisa vertebrar en un impuesto personal único toda la imposición directa. $\mathrm{Y}$ a ello se va con la reestructuración del Impuesto General sobre la Renta. El ministro de Hacienda to ha considerado como la upiedra angular del nuevo sistema y que supone, por lo tanto, el asentamiento definitivo de la reforma ${ }^{25} \mathrm{n}$. Lo mismo podíamos ver escrito en la exposición de motivos de la Ley con palabras más com. pletas, porque llegan a hacerse cargo de las dificultades prácticas del deseo en este punto y están llenas de un equilibrio realista. Reconozcamos un retraso en nuestra legislación tributaria precedente en cuanto al impuesto personal único, pero que este reconocimiento no sea más que un potente acicate para recuperar el tiempo perdido, con toda la prudencia que sea necesaria, pero en medio de una dinámica que no conozca reposo hacia el perfeccionamiento. $\mathrm{Y}$ nunca se olvide que

24 No podemos detenernos ahora en analizar uno a uno los tributos indirectos, ni siquiera someramente. Del nuevo tributo indirecto sobre el "Tráfico de las empresas» se espera recaudar en el presente año unos 14.000 millones de pesetas, cifra esperada e inesperada durante el proyecto, y en su mayor parte repercutible en el consumidor, que, junto con la total estructura del citado impuesto, necesitaría, por su novedad, un análisis moral de suficiente ponderación.

25 Discurso al Pleno de las Cortes Españolas el 22-12-1964. 
toda la imposición indirecta ha de ir encaminada hacia ese ideal im. puesto único de las personas.

Con satisfacción hay que reconocer que el primer paso se ha dado. $\mathbf{Y}$ es posible que se objete que es sólo teórico, porque se mantienen otros impuestos tradicionales directos agrupados alrededor de la nueva configuración del Impuesto General sobre la Renta, con la denominación y carácter de impuestos a cuenta y que, por lo tanto, se trata solamente de un mero juego de palabras carente y vacío de toda realidad objetiva. Estimamos-y no creemos que con excesivo optimismo-que era necesario ese paso previo al que deben seguir otros mu* chos. El impuesto personal único nunca podrá ser perfecto entre hombres, pero su pura teoria indudablemente seduce por lo sencilla, por lo justa, en cualquier clase de justicia que se considere, y por lo apta, no sólo para el fin primordial del impuesto de recabar fondos, sino también por los fines secundarios de una redistribución de renta nacional y de los demás propios de una política social y económica en diferentes coyunturas.

Por eso, si en cualquier parte de la nueva reforma tributaria hay que insistir contra la posible tentación del estancamiento, mucho más en el intento de logràr la relativa perfección del impuesto directo sobre la renta de las personas físicas. Es un peligro, no pequeño, que puede esterilizar el articulado y las intenciones de la exposición de motivos dignas de aprobación y de aliento. En ellos no ha quedado por sopesar nada, existencialmente importante, desde el punto de vista triple de la práctica, de la técnica y de la ley.

"Debe advertirse que el planteamiento de la imposición personal sobre la renta responde a un deseo de prudencia y tiene un carácter eminentemente práctico, con sacrificio en algunas ocasiones, de lo que sería la máxima pureza conceptual, pues al operar sobre los criterios de estimación de bases de los actuales impuesto de producto, no obs. tante su posible transformación en pagos a cuenta del general y definitivo, la determinación de la renta personal queda condicionada a los criterios de esos gravámenes previos, que no permiten alcanzar, cuando menos en un principio, un concepto plenamente subjetivo de la renta personal. Esto no obstante, el establecimiento de un Impuesto General sobre la Renta de las personas físicas supondrá no sólo un perfeccionamiento de las técnicas de distribución de las cargas públicas, al instaurar el medio más depurado para su distribución, según la capacidad tributaria, sino que, al mismo tiempo, desde el punto de vista de la política económica y social, se abren grandes posibilidades 
para dar a las circunstancias personales y familiares la condicion que en el tributo merecen... ${ }^{2 \sigma^{\prime \prime}}$

Téricamente, pues, perfecto todo y con todos los cabos atados, inchuso los de una dealización excesiva Prácticamente es aún pronto para juzgar, puesto que en realidad, totalmente, la nueva concepción de este impuesto empezará a regir el 1 de enero de 1966 . Y para esta recha, no está de más aquí un segundo toque de atención a lo que antes se dijo a proposito del articulo 14 que espera la trascendental aprobación por las Cortes de 1 a tarifa del Impuesto General sobre la Renta, en la que está el alma de la justicia de toda esta acertada y teorica simplificación del principal impuesto directo español. Esperemos confiadamente que la repetida tarifa concuerde con los ideales y principios expuestos Para el 31 de diciembre de este año, a la vista de la misma, se podrá hablar moralmente con más conocimiento de causa.

\section{SUELDOS Y MÍNIMO EXENTO}

Ante esta estructuración proyectada del impuesto de la Renta de Personas Físicas pierden importancia las peculiaridades de los cinco tributos que se reputan a cuenta del mismo. Admítasenos como mom tyo para que prescindamos ahora de ellos, aunque algunos, como la contribución tertitorial rústica y pecuaria, han dado bastante juego a comentarios, réplicas y contrarréplicas, incluso oficiales. Es lógico, porque la agricultura española, en profunda crisis y delicada situación, necesita un trato favorable desde muchos puntos de vista, no siendo el menor de ellos el fiscal, exigido firmemente por la doctrina social de la lglesia, de modo particular en la última encíclica sobre esta materia, la a Mater et Magistra 2 ? Pero necesitariamos demasiado espacio para la detención. $5 \mathrm{y}$

26 Ley de Reforma del sistema Tributario, exposición de motivos, III, pár. Cfr la nota det Minsterio de Hacienda del 9-2-65, que no pareció demafoualmente ni suficiente para levar la del mismo Ministerio editorial de $A B C$ del 14 dada el 19 , por fin otras puntualizaciones del mismo periódico el 24 del mismo a forial No cabe duda que en este aspecto hay una pro funda inquietud y quiza no bastan las palabras que provienen de fuentes autorizadas para calmarla, como las del señor Ximénez Soteras, F., Jefe del Servicio Técnico Facultativos No hay motivo de alarma en la agricultura por el aspecto tributarion, del $104-65$ si, pot una parte, sus afirmaciones y razonamientos son aceptables, por otra, en la misma contextura de la reforma hay necesariamente una serie de complicaciones cono la tramitación fiscal para las pérdidas y los beneflcios exiguos, de nueva y justísina creación, pero que implicará aunque sólo sea una contabilidad rudimentaria y otras domésticas burocracias que difícilmente encajarán en la psicología $y$ en nuvel cultural del contribuyente agricola. Cfr. el co- 
Por otro capítulo, es también muy debatido el impuesto a cuenta denominado sobre los rendimientos de trabajo personal. La razón es que muchos españoles tienen como única fuente de ingresos para desenvolver su vida, la remuneración que reciben por su trabajo, bien sea manual, liberal o de servicios, ahora ya determinado que en el futuro se consideren sin discriminación para efectos tributarios, en forma plausible. Por esa razón de ser gran número de contribuyente que sólo tienen este recurso de vida, se ha planteado preferentemente aquí la cuestión de los mínimos exentos, cuando en realidad estaría mucho mejor planteado en el tributo de conjunto sobre la renta de las personas.

De todas formas, a efectos de considerar los aspectos morales de la exención en cuanto a un mínimo, resulta indiferente para la doctrina que las oportunas consideraciones se hagan alrededor de uno o de otro tributo.

El principio fundamental podría enunciarse así: «En circunstancias nacionales ordinarias no es justa la imposición tributaria sobre ingresos que no llegan a un mínimo vital digno." En consecuencia, es preciso calcular estadísticamente el término medio (se legisla para la generalidad) que debe quedar exento. El problema se planteó en la Co. misión de las Cortes, es bien conocido y de él hemos hablado en otro lugar ${ }^{28}$. Triunfó el justo parecer de elevar el techo tributario exento a la línea de las 60.000 pesetas, en vez de quedarse en las 40.000 , si bien con la limitación de comenzar a tributar a partir de las 40,000 cuando los ingresos por el trabajo personal excedan de 60.000 pesetas anuales, respetando siempre esta cifra de cualquier mordedura fiscal.

La decisión fue lógicamente justa teniendo en cuenta que en aque. Ilos días los cálculos que se hacían por diversos conductos nos daban un presupuesto mínimo diario para una familia media en Madrid de 168,90 pesetas, que totalizan una cifra anual alrededor de las 60000 pesetas. un poco sobrepasadas. $\mathrm{Y}$ los presupuestos en las restantes provincias españolas para una familia tipo semejante giraban alrededor de la cifra madrileña.

Los precios, el desarrollo, la inflación..., han variado sustancialmente en el pasado año los supuestos de las líneas anteriores. A fines de 1964 el presupuesto aludido era de 184,13 pesetas, y desde entonces acá sigue un ritmo ascendente. Los sueldos, en pesetas, de 1958, pasaron desde 1963 a 1964 de 260 a 267,9 , con un aumento del 3 por 100 ;

mentario de Gómez-Aparici Jajares, R., en los Comentarios a la Ley de Reforma del Sistema Tributario, ya citada, pp. 7-23. El señor Allende García-Baxter, T. interpeló al Gobierno sobre la política agraria en la sesión de Cortes del 27.4 de este año: el segundo de los puntos que estima principales se refiere a la ordenación financiera apoyándose en la encíclica "MM" para abogar por la necesidad de que sean tenidas en cuenta las características y la situación actual del campo en cuakquier medida fiscal.

${ }_{28}$ Cfr. Cuadernos para el Diálogo, diciembre 1964, p. 29. 
el índice de precios en los mismos años subió del 116,6 al 122,8, según los datos de la Contabilidad Nacional o del 117,2 al 120,6 según los del I. N. E. (para precios al por mayor), mientras que el coste de la vida según el mismo I. N. E. pasa del 127,5 al 137,4 para los mismos años ${ }^{29}$. Todos los datos aducidos y otros semejantes convergen en la construcción de una respuesta únánime: rápidamente se ha quedado pequeño el mínimo exento, que hay que elevarlo a las 70.000 pesetas, con la atención permanente a las circunstancias aludidas de precios, coste de vida, etc., para seguir actualizándolo conforme a ellas, al menos cada bienio. Si elevando este techo tributario del mínimo exento en la forma indicada se previera un colapso total de la Hacienda Pública 0 , al menos, de una gran importancia, el bien común podría autorizar que se tocara tributariamente ese mínimo teórico exento, pero antes se necesitaría poder contestar afirmativamente a estas dos preguntas: a) Los gastos presupuestarios ise proyectan en función de los impuestos que justamente se pueden reclamar? Porque si en esta pregunta la respuesta fuera negativa, de manera que el camino recorrido se realizara inversamente, es decir, de proyectar gastos y después obtener como sea los ingresos para aquellos gastos, no habría justificación alguna para tal recaudación salvo si el gasto así concebido fuera inaplazable y de extrema urgencia para el bien común general; y b) ¿se ha apretado más la presión tributaria, como primera providencia, en las rentas superiores al mínimo exento? Porque si la respuesta fuera aquí también negativa, tampoco habría justificación para el porcentaje exigido, a menos que efectos secundarios, como daño al estímulo o grave perjuicio en la formación de capitales necesarios y ahorro imprescindible, a la luz del bien común, aconsejaran otra cosa.

Queda iniciado el camino, con las líneas anteriores, para poder advertir moralmente que la exigencia de revisión del mínimo vital se hace ya necesaria otra vez a pesar del poco tiempo transcurrido; que ha de tenerse muy en cuenta lo que exige el artículo 114 de la ley, y que, a pesar de la molestia que pueda suponer para las autoridades financieras, la evolución española de costes, salarios, poder adquisitivo de la peseta..., tal revisión ha de ser frecuente, sin caer en la fácil tentación de bloquear la cifra mínima, dejándola anclada durante mucho tiempo en una estática que lleva dentro de sí el germen de la injusticia de rápido crecimiento.

\section{CONCLUSIONES}

Dentro de unos días se va a cumplir el año de la promulgación de la Ley de Reforma del Sistema Tributario.

29. Los datos están tomados del Boletín de Acción Social Patronal, Anuario Estadistico del I.N.E. y de Información Comercial Española, marzo 1965, tabla A, evolución de las variables macroeconómicas, 1954-64, pp. 22-23. 
El tiempo transcurrido, sin embargo, no es suficiente para poder enjuiciar los resultados prácticos producidos, sobre todo teniendo en cuenta que la entrada en vigor se está realizando en forma escalonada.

Por eso los pareceres de las revistas económicas, de las memorias bancarias o de importantes sociedades, etc., se muestran justificadamente cautos en sus afirmaciones, naturalmente relativas a los aspectos más técnicos de la Ley. En contraste, los comentarios, artículos, estudios y previsiones parciales son numerosísimos ${ }^{30}$, con tendencias y apreciaciones para todos los gustos.

Esta provisionalidad crítica en el campo técnico y práctico influye también consecuentemente en el campo moral, cuyos juicios, por lo mismo, son parciales y no totales, provisionales y no definitivos, abiertos y espectantes.

Con estas limitaciones, al moralista le parece que, en general, la Ley de Reforma del Sistema Tributario, junto con la Ley General Tributaria de 1963, supone un sincero, profundo y realista intento por sistematizar y actualizar nuestra Hacienda Pública, a pesar de todos los defectos e imperfecciones.

Teóricamente hay la suficiente base para realizar los perfeccionamientos que moralmente eran requeridos en nuestro sistema fiscal en cuanto a los tres apartados de a) renovación y simplificación, b) progresividad y aspecto social y c) tributación directa e indirecta. En todos se deja la puerta abierta para caminar en una constante línea de pro. greso indefinido.

Prácticamente el mayor peligro, apuntado en algunos aspectos ya, lo encontramos en la posibilidad de una inercia que considere lo adquirido como algo perfecto e inamovible a pesar de las afirmaciones contrarias en la exposición de motivos y del articulado, con lo que pretextos para el incumplimiento y reales injusticias se pueden infiltrar rápidamente. En especial se necesita, incluso desde los primeros tiempos de vigencia, una atención a la renovación del articulado, a una progresividad mayor $\mathrm{y}$, en consecuencia, a la mejor distribución de la renta; un equilibrio más igualado entre los impuestos directos y los indirectos y la atención en este año, tenidas en cuenta las circunstancias económicas nacionales, a una aprobación ponderada y justa de la tarifa del Impuesto General sobre la Renta de las Personas Físicas.

\section{Comillas, 31 de mayo de 1965}

30 Prácticamente todos los números del presente año de las revistas de economía publicadas semanalmente, El Economista y Actualidad Economica, tienen consideraciones sobre los aspectos diarios que va provocando la nueva Ley tributaria; claro es que desde sus puntos respectivos de vista. Aparte de las obras citadas podemos indicar la de Carretero Pérez. A., El Sistema Tributario Español de 1964, Madrid, 1964, de carácter práctico, etc. Y ahora se ha anunciado un número monográfico sobre el tema y que promete ser muy interesante, del Boletín de Estudios Económicos de Deusto, correspondiente a enero-junio del presente año. 